\title{
PROBLEMS OF DEONTOLOGY IN MODERN MEDICINE
}

\author{
Masna-Chala Oksana ${ }^{1}$ \\ Matolych Ulyana ${ }^{2}$
}

DOI: http://dx.doi.org/10.30525/978-9934-571-31-2_7

\begin{abstract}
The article "Problems of deontology in modern medicine" provides: inoculation of deontology in the learning process, the word of the doctor, deontology of medicinal treatment, deontology in pediatric, deontology of family medicine, deontology of hospice, deontology of euthanasia and abortion, deontology of transplantation, medical error. By accumulating experience of treatment for thousands of years, doctors have constant problems with solving the moral and ethical principles of their profession: responsibility to themselves and to society for their professional activity in choosing the means and methods of treatment; donation and transplantation; artificial interruption of pregnancy and euthanasia, and many others. Today there is a fantastic progress in medicine, medical technology and the invention of effective therapeutic agents. However, fullfledged medical activity is possible only on condition of accordance with the rules of medical ethics, deontology. Future physician should receive the first notions about the deontology from the first days of studying at a university, before arriving at clinical departments. We mean the moral and ethical principles of the educational process in the dissecting room, during the educational experiments with test animals, and especially-in the study course "Caring for the sick." Only on this condition, the student, having come to the clinical department, will have the opportunity to be correctly orientated in the studying deontology. The issue of deontology, especially in our time, needs to be given considerable attention throughout the course of postgraduate education, that is, when passing courses of perfection, precertification cycles. In the healing of a sick person, the word of the doctor is very important. A good doctor starts treatment with a good word. The words and behavior of the doctor in communicating with the patient should
\end{abstract}

\footnotetext{
${ }^{1}$ Candidate of Medical Sciences, Associate Professor,

Danylo Halytsky Lviv National Medical University, Ukraine

${ }^{2}$ Candidate of Medical Sciences, Associate Professor,

Danylo Halytsky Lviv National Medical University, Ukraine
} 
be chosen so thoughtfully, carefully and balanced, as in the situation with selecting the doses of potent drugs. The confidence and perseverance of the doctor, shown in a friendly and soft form, also help to establish an optimal contact. By showing an appropriate respect to the patient, the doctor must still maintain a certain distance, prevent the backslapping. Summing up reflections on the problem of medical errors, it will advisable to give such advice: "Do not be afraid to trust your common sense, keep in the heart love to your patient and did not be afraid to make an error, really humane doctor almost do not make it".

\section{Introduction}

By accumulating experience of treatment for thousands of years, doctors have constant problems with solving the moral and ethical principles of their profession: responsibility to themselves and to society for their professional activity in choosing the means and methods of treatment; donation and transplantation; artificial interruption of pregnancy and euthanasia, and many others.

Moral-ethical and psychological aspects of medical activity, which were formed during centuries, emerged in different ways depending on the development of medicine and social conditions. Today there is a fantastic progress in medicine, medical technology and the invention of effective therapeutic agents. However, full-fledged medical activity is possible only on condition of accordance with the rules of medical ethics, deontology. Accordance with deontological principles in medicine is quite a difficult thing, but in general medicine is extremely complicated and very sacred work, one of the few altruistic professions [4, pp. 50-64; 9, pp. 13-14].

\section{Inoculation of deontology in the learning process}

Practice shows that either practitioners or future doctors are not taught deontology in an appropriate way. At the same time, in particular deontology determines the level of medicine, and science only improves it [12, pp. 5-8, 12-15; 3, pp. 102-103, 181-182, 266; 10, p. 8].

Future physician should receive the first notions about the deontology from the first days of studying at a university, before arriving at clinical departments. We mean the moral and ethical principles of the educational process in the dissecting room, during the educational experiments with test animals, and especially-in the study course "Caring for the sick" [9, p. 71]. 


\section{Masna-Chala Oksana, Matolych Ulyana}

Only on this condition, the student, having come to the clinical department, will have the opportunity to be correctly orientated in the studying deontology. Also, questions of deontology should be emphasized during conducting practical training in a studying period. The student's knowledge of the principles of deontology should be paid special attention during the exams, and especially in internship, which is the responsible period of the specialist's development. Thus, the whole educational process should be subordinated to it. In the process of studying there should be constant training of young people to be a Human, and human being the doctor, the formation of his deep respect to the human person, a sympathetic attitude to sick person. A medical student needs to persistently train the ability to combine rational and emotional parts in his work.

The technicalization of medicine should not discourage the doctor from the patient. At the same time, fundamental theoretic knowledge and good possession of practical skills allow the doctor to be quickly and easily oriented in the biophysical aspects of the disease and, therefore, devote more time to human contact with the patient. Deliberative penetration into the philosophical nature of medicine conduce to this, because without understanding the philosophical categories and concepts it is impossible to be optimally determined in the interrelationships between the various risk factors and signs of pathology, logically associate and analyze diagnostic information, combine the spiritual and material in medicine.

In many countries, obtaining a medical degree, graduating students receive a certificate of the aquired philosophical education. We still do not practice this for some reason.

Do you need to study deontology as a separate subject in medical institutions? It is expedient, primary for understanding theoretical issues of deontology. Practical aspects of deontology should be studied throughout the course of study at each clinical department. The most effective way of inculcating them to future doctors is a personal example of the teachers, all the medical staff of the basic training clinics, the prevailing atmosphere there. Observance by the principles of deontology by medical teachers should be brought to the rank of absolute. Any violation of deontology in the full view of students - it is much worse than a possible mistake of the teacher during some medical manipulations $[9$, p. 72].

Pedagogy teaches that students have the ability to unconditionally copy the behavior of their teachers. It is appropriate to remind that pedagogy also 
believes that there are no bad students, but there are bad teachers. You can teach a student to treat patients, but professional morality and ethics can be only instilled, which is much harder.

The issue of deontology, especially in our time, needs to be given considerable attention throughout the course of postgraduate education, that is, when passing courses of perfection, pre-certification cycles. Deontology, as well as medicine in general - this is not once-for-alltime formulated moral and ethical code. It should be remembered that deontology, like all science, accepting dogma, committs suicide. Therefore, all changes that take place in medicine, economics, society as a whole are reflected in it. Deontology is closely connected with psychology, and human psychology is the Universe, and therefore it is impossible to predict all the psychological situations in the relationship between "the doctor - the patient".

\section{The word of the doctor}

In the healing of a sick person, the word of the doctor is very important. Indeed, many ailments are iatrogenic, i.e. inspired by thought, word, including the word of the doctor, sometimes ill-considered, indifferent, angry. "The word is the same effective in treating as a scalpel in surgery, under the sole condition - if they are able to control it. Scalpel touches the body, but we touch the soul by using the word, and therefore it, like a scalpel, can not be "dull" [2, p. 258]. A good doctor starts treatment with a good word. The words show initially the doctor's attitude towards the patient, healer's attitude to patient, or that unfortunately often can be seen, the attitude of the owner of medical diploma to the object of his professional interest. The difference between the owner of the medical diploma and the Doctor, according to our opinion, lies primarily in the fact that the first one more-or-less successfully treats the sick body, and the second one, i.e. a real doctor who treats the body and the soul, which are coherent whole, while the person lives. [9, pp. 23-25].

The words and behavior of the doctor in communicating with the patient should be chosen so thoughtfully, carefully and balanced, as in the situation with selecting the doses of potent drugs. They must initially mobilize and strengthen the patient's faith in recovery, especially while implementing doctor's recommendations. It is necessary to fix the attention of the patient and his relatives on positive tendency in the course of the disease. If the 
doctor succeeds - this is already a big step to victory over the disease, the commom victory of the doctor and the patient.

When talking to a doctor, a demonstration of the doctor's confidence and his self-esteem adds the patient optimism and faith in the power of both the doctor and the medicine in general. But you should beware of such manifestations on behalf of the doctor as self-confidence, vanity and disregard. Optimism should be strongly dosed as drugs because its excess can give the most unexpected results, even including patient's refusal from the surgery, or vice versa-alert him, even including the faint of the doctor.

The conversation of the patient and doctor should not turn into an unproductive chatter, but at the same time it should not be emphasized officially. Especially at the first conversation with a sick the doctor should not grudge the time to listen to the patient, but that time should be used most rationally. This conversation should be as informative as possible, and somehow psychotherapeutic. The last one involves removing fears, physic tension, the formation of hope for a propitious prognosis and belief in the doctor. Of course, you should avoid extremity when a weak professional treats or operates carelessly and at the same time, "give the patient runaround." [9, p. 28].

It is desirable that in the context of a conversation with a sick person, doctor do not bring to his attention any prior conclusions about the patient's condition, the subsequent treatment and the prognosis. As a result of the subsequent examination, they can change, sometimes quite dramatically. Then, firstly, the doctor will lose the patient's trust. Secondly, it may be perceived by the patient as a sign of the insufficient competence of the doctor, of his simplification to treatment and once again it will lead to disappointment in the doctor.

As a result of the first conversation, the doctor, though he may not yet have a clear imagination about the illness and treatment, however, he should inform the patient of the overall positive conclusion, as well as his assumptions about the treatment. In the future, the patient will be referred on the additional and laboratory examinations, if necessary - to consult another specialist.

In some cases, when the doctor doubts in the diagnosis before the results of additional studies, or if there is reasonable suspicion of the presence severe illnesses in the patient, the patient should be said that the 
survey has not yet been finished, but the "propedeutic" treatment can be already started.

By no means it is possible to tell the patient that he has no illness, so he didn't pay attention to their nasty, painful feeling and so on, even if the doctor made sure that it is truth. It is incompetently in the contex of deontology, because if it is only functional neurogenic pathology, then such words of a doctor will lead to its strengthening, to its migration into worse and more symptomatic state. After all, the patient will seek other doctors, and by that time such phenomena can increase, and then another "better" professional will find his illness.

By the way, from the standpoint of observing the principles of deontology, it is not preffered to cancel appointments made by another doctor. If such a need has already arisen, then this should be done in such a way as not to disavow the actions of your colleague and thus not give the patient a reason to believe that he has been damaged by previous treatment. If this happens then be prepared that the treatment you have prescribed will cause the patient to doubt because of the "previous unsuccessful treatment experience". And we already know that the effectiveness of treatment is inversely related to the doubts in its effectiveness.

Therefore, it is expedient to tell the patient: "The medicines you have taken up to now have already done their job. At this stage of the illness, I will prescribe you a further course of treatment. But these new drugs can only act on their own, so now you have to stop taking the previous medication".

During the first visiting of the doctor the patient should be prescribed at least the placebo, because it would free the doctor from the hasty appointment of drugs even before diagnosis and at the same time will show the sick person that the doctor informally approaches to "the next patient,» and he appreciates him with professional interests and sympathy for his painful sufferings, understands that the patient needs help now, not after passing all additional examinations etc. It is a significant psychological moment in the profession of a doctor, especially with patients who may be "fixated" on his illness and (from their perspective) on doctors' indifference and incompetence [11, pp. 9-10].

The doctor's true art lies in the ability to present patient, if necessary, the harm of his unhealthy habits (smoking, alcohol abuse, overeating, etc.),so he become aware of this, but at the same time not to be so fixed on them, that it would become the iatrogenesis. 


\section{Masna-Chala Oksana, Matolych Ulyana}

It is clear that the appointed approximate "script" of the patient's visiting to the doctor should not be taken as an axiom, but only help the doctor in the basic requirements of deontology regarding the installation of the first contact with the patient.

If such a first meeting with a sick person occurs in a hospital ward, it has its own peculiarities. It should be remembered that the patient may not want his conversation with a doctor to be heard by neighbors in the ward. Therefore, it is advisable not to carry out an examination of the patient there, but if there is no such possibility (for example, a lying patient), then the conversation should be in a low voice without attracting attention of others. It should be taken into account that the patient from the first meeting with a doctor already receives enough information about him from other patients in the ward, as a rule. The mental state of the patient is influenced by the stories of the neighbors and their condition. Therefore, the doctors contrived cheerfulness and optimism will be inappropriate, when another patient groans next to him. Such a neighborhood should be avoided, especially when the patient is preparing to surgery, because in such a way an aura of fear and patience is created around the patient that dramatically affects the course of treatment, surgery and postoperative period.

In many hospitals, for some reason, there is not enough attention paid to the psychological compatibility of patients that are in one ward. Being in a permanent state of psychological discomfort for weeks or even months, people are unsuccessfully treated for somatic and other diseases, most of which lies exactly in neurogenic reason. Therefore, the psychological climate not only in the medical team, but also in the team of patients is very important from the point of view of compliance with the requirements of deontology. Not always having the opportunity to create a sufficient household comfort for patients, doctors - from the chief doctor to a nurse - should consider their holy duty to develop a sufficient psychological comfort for the patients, not for a moment forgetting that it is a significant medical item.

Unfortunately, our current economic and organizational conditions do not always allow you to avoid such situations in hospitals, so if the situation cannot be corrected in organizational relation, psychoprophylaxis must be applied, including the psychopharmacological effects on the patient. In addition to this, this is required by the deontology statute, as mercy with respect to the patient on the part of the medical staff. This applies to 
patients, both surgical and therapeutic parts because some doctors think that given psycho-pharmacological training is only one of the stages in preparation for the surgery.

In a conversation with patients, any thought should be taught extremely clearly, because the peculiarity of the human mentality, especially in extreme cases, is such that the person hears mainly only the desirable for her. Therefore, not very clear information or recommendation can be misunderstood.

Speaking with the patient, listening to his complaints and collecting the anamnesis, the doctor should not focus too much on the most striking symptoms. First of all, he must evaluate the patient on the basis of what he has heard and seen, as a total organism, and only then analyze the details, symptoms.

The psychological state of the patient after his contact with a doctor is heavily dependent on the doctor. Not only the doctor tries to comprehensively evaluate his patient, but also develops his vision of a physician, and not only as a physician, but also as a person, in close conjunction of both characteristics. This is especially concerns those doctors with whom patients have to contact for a long time. And not only the appearance and behavior of the doctor, how he talks to patients and colleagues, but also civic position, behavior in everyday life, careful attitude to the hospital property-all this and much more characterize the man-doctor thoroughly, it is fixed by the patient's attention or his relatives. By the way, for some reason it is believed that only in the West the image of a doctor is determined even by the car model. All of this should be remembered, then you would not surprised why patients love this doctor more than the other, which has a diploma with honors, and is trained abroad.

Thus, deontological recommendations for establishing contact between a doctor and a patient are leading to the following. Communication should be primarily aimed at establishing trusting relationships, and then - to obtain the necessary information for a doctor. You need to be able to put yourself in the patient's position or his relatives, first of all to remove their feelings of fear of their behavior, confidence, but not self-confidence. The appearance of the doctor should be neat, the behavior - calm, the mood quite optimistic. If the doctor smokes, the patient should not even guess about it during the conversation - it can ruin both contact and trust. The belief of the patient and his relatives that exactly this doctor and this 
medical institution will be able to help the patient eliminates most of the deontological problems. The confidence and perseverance of the doctor, shown in a friendly and soft form, also help to establish an optimal contact. By showing an appropriate respect to the patient, the doctor must still maintain a certain distance, prevent the backslapping [2, pp. 258, 260; 7, pp. 7-8; 9, pp. 25-31; 10, pp. 35-36; 11, pp. 9-10].

\section{Deontology of medicinal treatment}

The current issue of deontology in our time is the problem of uncontrolled use of drugs, in particular, widespread self-treatment. In fact, doctors have lost control over drug treatment. Many people believe that since there is now free access to almost all existing medicines in the world, and media advertising creates a panacea image for many drugs, it can be treated without the participation of a doctor. Moreover, the doctor does not always find it necessary and possible to prescribe the patient the desired medication. Not always communication between a doctor and a patient in such cases is in compliance with the principles of deontology. Namely their possession can greatly contribute to solving the problems of self-treatment and uncontrolled use of drugs. Doctor's patience is required here, taking into account the cultural and educational level of the patient. The optimal option is to have a conversation when the patient "independently" comes to the conclusion of the correctness of the doctor. Otherwise, having listened to all the fears and prohibitions, he will still do his own way. In such a situation, the authority of the doctor positively and effectively works in his favor only when it has been acquired by a doctor before. If the doctor meets a patient for the first time, it woud be convinient for doctor to see a piety of the patient which has been developed and implanted by other doctors. It should always be remembered and work in this way with patients not only on their own authority, but also on the authority of the medicine in general. Therefore, face-to-face criticism and criticism behind other doctors' back to patients is unacceptable, arrogant attitude towards his junior colleagues, adjunct medical staff. Such disrespect may eventually come back to bite those who allow it.

If a patient asks a doctor to prescribe him one or another drug that the doctor has no reliable information about, it is inadmissible to indiscriminately criticize this drug because after a while you can "step on your own rake". In addition, another doctor can give the patient detailed 
and positive information about the indicated drug and thus will be greatly undermined in the eyes of this patient (or even the entire chamber or family of the patient) professional authority of the doctor, in this case, as in general in medicine, baselessness and hasty conclusions, their categoricalness is unacceptable because they work against a doctor.

Should I agree with a patient who insists on prescribing one or another medicine, which is advertised as a "panacea" and "very helpful to a neighbor", if the doctor doubts in the expedience of using this drug, is not confident in its positive properties? In this case, the answer should be based on the doctors' commandments: "Do not hurt the patient!" [9, pp. 26-28].

But now there are much more complex situations. What if there is a need to use a new drug, but is it still not well examined? Whether to tell about it to the patient and thereby to face his possible resistance, refusal from the preparation, which eventually will lead to deterioration of the patient's condition? Whether to be insured by a patient's consent or consent of relatives (parents of a child)? Will such information provoke psychogenetic negative changes in the treatment efficacy?

The answer to these questions should be determined by the sociopsychological contact that the doctor manages to establish with the patient. If the doctor is confident that this contact is sufficiently positive and stable, he may be more candid with the patient. In addition, the whole medicine experience shows that the doctor's confidence in successful treatment, in this case - with the use of this drug, is necessarily passed to the patient. Finally, in this case, the doctor must put himself in the patient's position. The confidence of the doctor should be determined by his professional skills, and any doubt should be interpreted in favor of the patient, i.e. the inappropriate use of the drug. By the way, the indicated deontological tactic should be also in the using of new therapeutic methods. [3, pp. 62-63, 168].

Our population in general is not very wealthy, and prices for most even commonly used drugs are quite high. Therefore, the drugstore workers pharmacists should more observantly offer visitors drugs, to take care of the possibility of replacing expensive drugs with cheaper analogues. The same circumstance should be taken into account also by doctors in the appointment of medical treatment. The physician should conduct a social estimation of the treatment he recommends, and not only the drug-included.

According to the "International Code of Medical Ethics" [11, p. 22], the doctor should not financially influence the free and independent execution 
of professional decisions in the interests of patients. Putting the patient in such a situation, when he actually turns out to be insolvent according to the proposed treatment, the doctor should, putting himself in the patient's position, take into account how negatively it can influence not only psychological condition of the patient, but also the progress of the disease, at the end of treatment. Payment for treatment should be differentiated in relation to each patient, and the doctor should form his though of the financial capacity of a sick already during the first conversation with the patient, but in any case without fixing his attention on it. Otherwise, this may lead to distancing between him and the patient, the emergence of patient's negative, sometimes carefully concealed, feelings. The last ones may adversely affect the course of the illness, the patient may turn to selftreatment or consult incompetent healers.

In most cases, a doctor can avoid many of these problems if he is guided by ancient Latin wisdom, "Medica mente, non medicamentum" - treat your mind, not medicines.

\section{Deontology in pediatric}

Speaking about deontology in medicine, it is necessary to highlight the issue of deontology in pediatrics. [9, pp. 49-52]. Surely communication with the child, and in most cases, simultaneously with his relatives, requires from the doctor special approaches, good knowledge of age psychology and certain aspects of pedagogy of different age groups. If you are talking about establishing contact with a child, you must take into account the age and individual characteristics of the child's mentality. Establishing good contact with the child guarantees the doctor to be trusted by the child's relatives and the success in communication in general. For a doctor who deals with adults, it is naturally easier to establish a psychological contact with them, put himself in their position, recognize their psychology. In pediatrics, there is a psychological barrier between the doctor and his small patient, it is much more difficult to understand the psychological state of the child, fully recognize his experience. And at the same time, the pediatrician is forced to establish psychological contact with relatives of the child, who require more special deontological approach. Because of illness of the child they are confused, nervous, and so on. Therefore, when dealing with them, this should be taken into account. To some extent, one should proceed from the fact that parents know their child better, they understand him not only 
mentally but also by the heart, they know and understand what the doctor does not know and can not know [6, pp. 138-147, 184-189].

It should be taken into account that parents give unconditional priority only to their sick child, so it is inappropriate to talk with them about any objective material and organizational problems that have an impact on the course of the diagnostic and treatment process in relation to their child. They are not interested in the doctor's availability, you should always find time for them, otherwise they can gather the necessary information from other sources. When comparing this information with further information from the attending doctor, some differences may occur, which will negatively affect the relationship with the parents and, often, the course of the child's treatment.

One of the main principles of deontology in pediatrics is the inadmissibility of deceiving both parents and children. Children very thinly feel falseness, once being deceived, dramatically lose their trust in the doctor. If the doctor is allowed to bluff a sick child (promises that obviously painful manipulation will be painless, etc.), it is a testament of the imperfect possession of deontology, to a certain extent-a testament of the low professional skills of a pediatrician [3, pp. 124-125; 9, pp. 49-52].

Talking with relatives you should be in no hurry, explaining the condition of the child not only with the use of special medical terms, misunderstanding of which only makes parents malicious and can cause various negative reactions. All statements of the doctor should be clear, but unambiguous, well-reasoned and not controversial. It must be remembered that the parents of a seriously ill child tend to hear only what they want to hear.

If the parents do not give consent to the child's admission to hospital or conducting urgent surgical intervention, in connection with which there is a threat to a child's life, and cannot install psychological contact with them, the doctor has a moral right to take all responsibility on himself, but should not interfere with the child's parents [2, p. 258].

The fear is dominant in the relationship between the doctor and the child; the emotions prevail as in creatures more biological, than social, sometimes inadequate; they are uncompromising; experiencing even in early childhood and even not fully aware of the negative emotions from communicating with a person in a white coat, the emotions can remain for life.

It is interesting that about 30 percent of children have an innate fear of the treatment in the dentist, and adults are afraid of this treatment up 
to 80 percent, by the way, it is confirmed by the objective biophysical factors.

If a child is panicked because of some manipulation, and especially surgical intervention, it is desirable to postpone it if there is no urgent need. In such cases it should be used not only psychological, but also psychopharmacological training.

First of all, the pediatrician should try to establish contact with the child, because parents, being convinced of the presence of such contact, will also trust the doctor. This confidence will be promoted by the behavior of the doctor, his appearance, the tone of conversation. If the doctor considers it necessary to insist on something for the parents of the child, this should be done softly and benevolently. On the part of doctor there should be an unconditional respect for the parents of the patient, regardless of their social status, but at the same time, it is not advisable to admit backslapping.

In pediatrics, the full responsibility of the child's health lies on the pediatrician. It is dehumanised and deeply unprofessional shift responsibility on the parents, especially in modern, sometimes very difficult socio-economic conditions, when family cannot provide adequate care, compliance with all requirements of valeology. This should be a foundation of the relationship between doctors and parents.

The realities of our present largely determine the peculiarities of both therapeutic technologies in pediatrics and deontological approaches.

Increasing of the diseases among children, including and congenital pathology, creates significant additional problems of deontological character - a complex psychological state of parents, a sense of certain doom and hopelessness. Generally, treatment of severe congenital pathology is quite valuable, on the background of the financial predicament of a significant part of the population causes additional moral-psychological discomfort in relations between doctor and parents of a sick child.

Taking into account that the growth of children's morbidity to some extent is determined by the negative influence of the environment, not only the natural, the work of doctor-pediatrician, in particular his preventive aspects, requires from him a new deontological approaches. This concerns the belief of children in the harmful influence of bad habits, explaining to parents the importance of the hygienic regime of children for their health. In this work, the doctor must demonstrate not only erudition, but also uncompromisingness, persistence, tact and individual approach, 
taking into account the psychology of children and parents. Of course, that's not easy to convince parents that this expensive and up-to-date baby gift, like a computer, could cause harm to his health if not follow hygienic requirements, and fashionable smoking is harmful even for the unborn child. The effectiveness of the pediatrician in this regard is largely dependent on his own belief in what he says.

High awareness of parents due to the not always conscientious advertising of drugs, including vitamins, should also be taken into account by the doctor when he communicates with his parents.

Not always we pay sufficient attention to the national affiliation of a sick child, to issues such as traditional food, hygiene, etc., to the psychological characteristics of the child, which has a significant effect on the doctor's communication with patients and even at better understanding of individual aspects of the progress of the disease in the interpretation of the relatives of the child [3, pp. 90-91].

\section{Deontology of family medicine}

Deontology of family medicine has its own specifics. It is assumed that a family doctor is almost a family member. He must have close psychological contact with each family, meant not only those family members who are currently sick or chronically ill, but also those who are practically healthy members of the family. These are people of all ages - from the early childhood to the late adulthood. Therefore, in his work the family doctor should be guided in pediatrics, in valeology, and in gerontology and, accordingly, observe their inherent deontological grounds.

In communication a family doctor should take into account, in addition to age-related features, the social situation of the family and its individual members, national specificities, religion (because the doctor treats not only the body but also must heal the soul), the problems that are in this family. The success in fighting with bad habits in the family depends on the establishing trusting relationships. Tips and recommendations of a family doctor should be based not only on medical grounds, but also they should take into account domestic realities of the individual families, the relationship between its members that define the psychological climate in the family [9, pp. 55-56].

You need to take into account the fact that in communication special medical arguments, although they are logical and balanced, do not always 


\section{Masna-Chala Oksana, Matolych Ulyana}

find the right way to the people and are not always properly perceived, sometimes irritate them, causing a negative reaction (even because of a simple misunderstanding). Therefore, we must be able to find and use only human arguments that are unstestood by ordinary people. In this way, the doctor achieves a much higher level of psychological contact, and hence better effectivness of the work. Particulary in the work of the family doctor, possibly as no other, trust, psychological compatibility and openness of both sides are key factors. Obviously, they are the main arguments in favor of family medicine.

\section{Deontology of hospice}

The growing number of hospices is becoming more and more widespread. The basis for this is a humane and well-minded view of human death. The peculiarity of these medical institutions is that their purpose is not a treatment, but medical care of the terminally ill, incurable people with the purpose to make life on the verge of death simplier, allowing them to live their last days comfortable, easier, painlessly. There is another philosophy of death, since the death of a hospitalized person in a hospice is natural, just like life itself [13, pp. 69-73].

Considering the deontology of hospice, we should conclude that the process of dying is accompanied by adding to the pain and suffering psychological and spiritual drama of the person devastated by disease. By the way, from the point of view of deontology, the best option for caring for a death-sick person is the care of the hospice doctors, usually in conjunction with the care of priests and dearest ones. Moreover, it does not necessarily have to be in the hospital room. But such a person can not be left in any way only under the care of relatives or, worse, alone [9, pp. 57-59].

Death is the last stage of life. Therefore, like all human life, it is required from doctors to have a professional, merciful and respectful attitude to the dying person [1, p. 45]. Such a person can not be treated as those who enters the final stage of his natural life. Everything should be done so that he, until her last breath, can feel himself alive among the living, full of love and care for her by others. In the feelings of a death-sick person, hope must prevail over despair, and relief must dominate the fear of non-existence. The duty of the doctor is to give hope to the hopeless and faith to those who lost it. But this does not need to be openly emphasized to the patient. This should 
be developed from the communication with a dying person. Explicit focus can give an undesirable result, contrary to expectations.

In the perception of dying person the doctors should be guided not only by medical categories, but also humanistic ones. The condition of the patient should be determined, first of all, by his subjective feelings, and only then by the biophysical aspects of the disease. And the doctor should affect these feelings both using symptomatic, mitigating measures, including painkillers and antianxiety drugs, and, more importantly, its relationship to the patient.

That's why so-called "Medical insistence" is forbidden, which involves the artificial prolongation of agony, condemning the dying person to burdensome medical manipulation, unreasonable deprivation of his consciousness. Quite often in such a way they try to avoid inconveniences for themselves, relatives of the sick person, and in no case alleviate the pain.

The complicated deontological problem is to report a patient true information about his hopeless condition. It is clear that a person has the right of being informed about the prediction of his life, has the right to make his most recent decisions. According to this information, we quote the The Charter For Health Care Workers: "The duty of telling the truth to the death-sick patient requires a differentiated attitude and human tact from the medical staff.

The truth about death can not be expressed in an indifferent message that is not related to the diagnosis and prognosis. No one can conceal the truth, but you should not even report it directly in its brutal reality. This bitter truth is to be passed in the fullness of love, calling to the communication of all those who for various reasons cares for the sick

It is about establishing trust, perception and dialogue with the patient, about the skillfully chosen time and words. There is a way of expression that is able to accept the request of the patient, to direct his knowledge of their own health. Those who try to be near the patient and affect his destiny, they are able to find the words and answers that allow them to communicate in truth and love.

Each individual case has its own requirements, according to the patient's vulnerability, with prediction of possible reactions (rebellion, depression, resignation, etc.). We have to be ready to meet any reaction calmly and tactfully. The most important thing is not the accuracy of the statement, but solidarity with the patient.

In such relationships, the prospect of death is inevitable and loses its power, which predetermines fear; the patient does not feel lonely and 
doomed to death. Thus, the given truth does not steal hope, but allows the patient to feel alive in the relationship between the complicity and solidarity. The patient does not remain alone with his patience and feels that he is understood without falsehood and in a collective union; he remains a person. His life, in spite of everything, makes sense and gains in importance that transcends the limits of death" [13, pp. 71-78].

By the way, one of the reasons why death-sick people sometimes get "help" from various crooks of medicine, after the official medicine retreats, is that not understanding all the heaviness and incurability of illness they give the dying people the hope [10, p. 49]. So it is very important that exactly the doctor give such a hope!

In the hospice it is especially distinctly manifested the close combination of medicine and religion, because the medicine, affecting the body, facilitates the heartache, and religious pastorship allows a person to perceive the pain and infirmity easier, finding hope, and it is an opportunity to victory over suffering and death.

\section{Deontology of euthanasia and abortion}

Euthanasia involves extremely complex deontological problems. Life is given to man by God and no one has the right to control it. Death is one of the stages of human life, therefore, God has to decide when it comes. "The Charter For Health Care Workers" states that "mercy, caused by pain and suffering of dying sick disabled children, mentally ill, people with incurable illnesses, old, etc., do not empower the ordinary or immediate euthanasia. In this case, it is not about helping the patient but about the intentional murder" [13, pp. 34-36, 86-89].

This could finally determine the medical and ethical problem. But the opponents have a question: "How does this position combine our duty with mercy to the incurable people, hard suffering man, whose entire life is built up essentially only on biological existence? Is it possible to ignore the will of the dying suffering person?".

According to mercy, medical staff certainly have to show it by providing assistance to the patient, making every possible effort to his salvation or relief of pain if unable to save, to providing the opportunity for a man to die with their Christian dignity.

The question about the "will" of the patient, a request to accelerate the end of his suffering and life itself is controversial. The Charter For Health 
Care Workers notes that "the requests of patients with serious diseases, who sometimes seek death, should not be understood as the expression of a genuine desire of euthanasia; almost always it's about full alarm call for help and love. In addition to medical care, the patient needs love, hot human and supernatural feelings, which can and should be given by his neighbors, parents and children, doctors and health service". We will add that very often the consciousness of such a patient is so obscure that we can not speak about some kind of conscious desire. A patient who feels a truly human attitude to himself is unlikely to ask to have his life interrupted. The doctor himself, as by the appropriate medical measures and using the full kit of deontological approaches, must do everything to ensure that the patient has not and would not have reasons for such a request. Euthanasia is never an act of mercy; it is an individual and public act of selfishness and escape from a hopeless situation. It destroys most foundations of psychological relations between the doctor and the patient, because the doctor ceases to be a guarantor of human life, and the patient applies to him for the uncharacteristic medicine action - murder [3, pp. 56-58, 75, 82, 119, 151, 216; 7, p. 11].

A person must fight for his life under all conditions, and the doctor should inspire him to do this, to help him with word and deed. The task of a doctor together with a priest is to achieve the aim when the hopelessly sick person has no fear of death, to replace it with hope, and there would be awareness of the possibility of victory over death, eternity of spiritual life that crosses over death.

The tragic reality is the increase in the number of HIV-infected and AIDS sufferer. Considering that today they are still practically incurable people, they must be surrounded by special care of doctors. It completely includes everything that is said about the deontology of the hospices, since the only thing that medicine can do for them is to relieve their bodily and spiritual suffering. No doctor has the right to refuse to provide such people with any medical care. This is especially true for practitioners. In cases of such a refusal, the deprivation of a specialist's right on medical practice should be inevitable, precisely on the basis of the neglecting of the principles of professional deontology [3, pp. 187-188].

One of the most "deontologized" medical measures is the artificial abortion. It is extremely burdensome in moral and ethical terms, even when it is based on medical necessity. Of course, abortion is a murder, a mass killing, because at least two people, a woman and a doctor, take part in 


\section{Masna-Chala Oksana, Matolych Ulyana}

it. Unfortunately, the realities of our modern life, as socio-economic and moral, led to the fact that according to the number of abortions, Ukraine occupies one of leading places in the world, and the number of abandoned children is dramatically growing.

The professional morale of doctors does not and can not admit any killing actions against life at any stage of it and under any reasons, except when there is a danger for woman's life. To remain faithful to this moral requirement, sometimes it is required from a doctor to be courageous and have self-control. To persuade the woman who is determined to have pregnancy terminated requires no less efforts. Obviously, the doctor will have to appeal to religious postulates that strongly deny the artificial abortion, stating the primacy of God's law. Life, even the embryo, is a gift of God and by an exceedingly great value, so that it can be compared with the most difficult social, domestic and other problems [3, pp. 117-118, 147-148]. To persuade the mother a doctor should mobilize all his life experience. It does not play any role that this specialist sometimes has to do that even several times throughout the day. Life is worth it, every life, because it is unique. For such a conversation you need the necessary situation, the interior of the room (lovely pictures of children on the walls, etc.), the mood of both sides for the appropriate conversation. The doctor himself must believe in what he says. It is possible that such a conversation should happen to a woman more than once. In the case of urgency, a woman can be offered to come in a day or two under some reason, which does not allow today to hold a surgery. And in the next conversation, the doctor's tactic should be adjusted, according to the results of the failure analysis during the previous conversation.

It is not effective to intimidate a woman by a result of abortion, because she is already full of fear and feelings.

The effectiveness of the conversation depends to a large extent on the fact how the doctor manages to find out the reasons for her intentions, carefully conceived by a woman.

The best would be if the doctor, convincing the woman to keep and give birth to a child, ask immediately after birth and after some time about the rescued child, and when a woman has problems he will be able to help her. It may happen that such a woman, under certain circumstances, becomes a kind of convincing "illustration" in the conversations of a doctor with other candidates for abortion [9, pp. 52-55]. 
The problem of abortion is largely related to contraception. In this case, religion clearly acts only for the natural planning of pregnancy [13, pp. 20-24, 3 , p. 137]. Of course, the role of the Church in our society is growing. But considering the fact that the effectiveness of contraception depends significantly on the level of murder of unborn children, i.e.abortions, then the question of contraception requires more flexibility. It is also substantiated by socio-medical factors: unsatisfactory living conditions and economic disadvantages, due to which the family can not afford to give birth not only two or more children, or even have a child at all; moral immorality and free views on sex; high incidence of various sexually transmitted infections. You can not close your eyes on these realities. It is obvious that the efforts of the state, lawmakers and society as a whole must be directed first and foremost to fight all this, and then the consequences of this - abortion will not be met frequently. And doctors should give recommendations regarding to contraception first of all based on our realities, and then they will be effective. These recommendations should be individual [9, pp. 54-55].

\section{Deontology of transplantation}

Transplantation is associated with certain bioethical problems, especially with regard to donation. At the same time, doctors and priests warn about the danger of temptation to take organs from a person whose brain death has not yet occurred. This is not even about the criminal intent of doctors. The temptation can be provoked by quite humane factors-the desire to save a patient-recipient, the influence of his relatives and professional ambitions and finally so extremely strong motive, as the possibility of defeat or defer death. But the donor is also a Human, whose life can not be taken by no one, even if it is on the verge of death. Thus, on one scales is the life of the recipient, and on the other - the death of the donor. In what direction the scales changes depends on the doctor [7, pp. 11-12].

In this situation is evident that from the side of doctors there is a need of active and goal-oriented explanatory work regarding transplantation, which should discuss not only when addressing some specific issues in each individual case of transplantation. If society is correctly oriented in the essence of the problem, and in each case it will be easier and easier to find solutions and, most importantly, it will be the most optimal and balanced.

There are people who are ready to leave their bodies for transplantation during they are alive. Obviously, we need sophisticated and delicate 
propaganda in this direction. This would be a good basis for the establishment of donor registers and banks, with adequate funding for this case.

Among the doctors who are proponents of such views on transplantology, and who believe that it has a negative impact on both the medicine and morality of society, there is a "crime without punishment", "industry of cannibalism" $[8$, p. 5]. To a certain extent, they are right, considering in the first place the unresolved of moral and ethical problems of this case. But if transplantation is carried out in compliance with the requirements of bioethics, is it possible that rescueing and prolongation of human life can be a sin, a kind of harm? It is possible that failures in transplantation are the result of the sinful actions of doctors. The successes are fulfilling the will of the Lord, embodied by the hands of the doctors. We think that the reflections given above have the right to exist, to be perceived or criticized [9, pp. 62-63].

At the same time, you can expect that in the near future the success of genetic engineering and surgical equipment to a certain extent will smoothen the sharpness of a given problem and the transplantation will go into a qualitatively different level.

\section{Medical error}

One of the most difficult deontological problems is the medical error. Errare humanum est - To err is human. The mistake of the doctor, by definition of the medical encyclopedia, is a conscientious misconception of the doctor in his professional activities. But a medical error may be a result of negligence, unfairness, and then it is no longer a mistake, it is a crime.

So, does a doctor have the right to make a professional mistake? How to behave yourself, if such a mistake has been made? How to communicate in such cases with the patient, his relatives? Is it possible to avoid communication in such cases?

Many large leading light in medicine openly declared a doctor's right to make a mistake, and the lack of a doctor's right to conceal it. The famous Austrian surgeon Teodor Bilroth wrote: "Only those with weak spirit, boastful chatterbox and tired of life are afraid to frankly talk about mistakes made by them" $[1$, p. 53].

Communicating with patients or his relatives after a doctor, which led to complications, disability or death of the patient, the doctor in any case should not set yourself the goal of justifying, to explain everything with 
objective, independent from him factors. The patient confined his health and life to the doctor unconditionally, and therefore to predict and avoid the influence of any side factors on the treatment process is the task of the only doctor and nobody else.

The duty of the doctor in such cases-to show a maximum of intelligence, noticing precisely the origin of the term "ìntelìgentus" which in Latin means "understanding" - in other words you should understand and alleviate their suffering. The doctor should put himself in the position of such a patient or his relatives and behave accordingly.

In case if between them and the doctor was not found satisfactory psychological contact, it is better to avoid such communication and in absentia, somehow to contribute to the alleviation of suffering, reducing his guilt.

The doctor must find in himself strengths and intelligence to constantly analyze his mistakes, which is a prerequisite that they do not repeat. Mostly those people are mistaken who are offensive, talkative, jump at conclusions, who are inclined to exaggerate their knowledge and professional skills, are unscrupulous.

It is believed that a smart person never repeats his mistakes, unless he makes new ones. But the history of medicine convincingly suggests that truly new mistakes are extremely rare, but people mostly sin repeating the old own mistakes.

Summing up reflections on the problem of medical errors, it will advisable to give such advice: "Do not be afraid to trust your common sense, keep in the heart love to your patient and did not be afraid to make an error, really humane doctor almost do not make it" [9, pp. 39-41; 5, pp. 102-1250, 4, pp. 9-11].

\section{Conclusions}

An overview of individual aspects of the problem of deontology in modern medicine gives reasons to conclude that medicine without deontology is a dead craft. It's like a body without a soul. Without spirituality there is no morality, there is no Human without morality, but without Human there is no Doctor. Therefore, the problems of medical deontology remains highly relevant in the context of consideration of the prospects and trends in the development of medical science and practice, and their absolute compliance is an indispensable condition of medicine success. 


\section{References:}

1. Amosov M. (1967) Dumky i sertse [The Thoughts and the Heart]. Kyiv: Dnipro. (in Ukrainian)

2. Bailin P. (1955) Tvory [Writing]. Kyiv: Dnipro. (in Ukrainian)

3. Lviv National Medical University of Danylo Halytsky (2009). Bioetyka v systemi okhorony zdorov'ya ta medychnoyi osvity. [Bioethics in the Health Care System and Medical Education]. Materials of the International research and practice conference, Lviv: Lviv National Medical University of Danylo Halytsky.

4. Biliynsky B. ( 2013) Medychni pomylky v onkolohiyi [Medical Errors in Oncology], - Lviv: Afisha. (in Ukrainian)

5. Biliynsky B. (2017) Profesor Anatoliy Ivanovych Hnatyshak [Professor Anatolii Ivanovich Gnatyshak A.] Lviv: Afisha (in Ukrainian)

6. Dolets'kyy S. (1974) Mysli v puti [Thoughts on the Road] Moskow: sovetskaya Rossiya (in Russian)

7. Halyts'ka vydavnycha spilka (2008).The Ethical Code of a Doctor [Etychnyy kodeks likarya] Lviv: Halyts'ka vydavnycha spilka (in Ukrainian)

8. Ivashkevich G. (1995). Prestupleniye bez nakazaniya [Crime without Punishment]. Lviv: Kray (in Ukrainian)

9. Masnyj Z. (2010) Problemy deontolohiyi v suchasniy ukrayins'kiy medytsyni [Problems of deontology in modern Ukrainian medicine]. Lviv: Halyts'ka vydavnycha spilka (in Ukrainian)

10. Orel L. (1999). Spirituality of Religion in Medicine and Healing. [Dukhovnist' relihiyi v medytsyni ta tsilytel'stvi]. Lviv: Spolom. (in Ukrainian)

11. World Health Organization, World Psychiatric Association UN, Association of psychiatrists of Ukraine (1996). Prava lyudyny ta profesiyna vidpovidal'nist' likarya u dokumentakh mizhnarodnykh orhanizatsiy. [Human rights and the professional responsibility of the doctor in the documents of international organizations]. Kyiv: World Health Organization, World Psychiatric Association UN, Association of psychiatrists of Ukraine.

12. Tereshkevych D.-H. (2008) Bioetyka v systemi okhorony zdorov'ya ta medychnoyi osvity [Bioethics in the System of Health Care and Medical Education]. Lviv: Svit. (in Ukrainian)

13. The Pontifical Council for Pastoral Care in the Health Care (1995) Chartiya pratsivnykiv okhorony zdorov'ya. [The Charter of Healthcare Workers]. Vatican: The Pontifical Council for Pastoral Care in the Health Care. 